\title{
Clostridium septicum fatality: diffuse bowel necrosis associated with cocaine abuse and agranulocytosis
}

\author{
William H. Jacobsen ${ }^{1}$, Joseph D. Losek ${ }^{2}$, Evert A. Eriksson*3 \\ ${ }^{1}$ Department of Medicine, Medical University of South Carolina, Charleston, United States \\ ${ }^{2}$ Department of Pediatric and Medicine, Medical University of South Carolina, Charleston, United States \\ ${ }^{3}$ Department of Surgery, Medical University of South Carolina, Charleston, United States
}

Received: June 28, 2015

DOI: $10.5430 /$ css.v1n1p34
Accepted: July 29, 2015

URL: http://dx.doi.org/10.5430/css.v1n1p34

\begin{abstract}
Spontaneous, non-traumatic gas gangrene due to Clostridium septicum is a rapidly progressive infection with a high mortality rate and most commonly presents with soft tissue myonecrosis. Predisposing factors include gastrointestinal pathology, malignancies and immune deficiency disorders. To our knowledge cocaine induce bowel ischemia as a predisposing factor for Clostridium septicum sepsis has not been previous reported.
\end{abstract}

Key Words: Bowel necrosis, Clostritium septicum, Cocaine abuse, Agranulocytosis, Bowel ischemia

\section{INTRODUCTION}

Spontaneous, non-traumatic gas gangrene due to Clostridium septicum has a high mortality rate of $67 \%$ to $100 \%$ with most deaths occurring within 24 hours of illness onset. ${ }^{[1]}$ Neutropenia and gastrointestinal pathologies which are commonly found in these cases permit bacterial assess to the bloodstream leading to bacteremia and most commonly presenting with soft tissue myonecrosis. Predisposing factors include gastrointestinal surgery, colonic cancer, diverticulitis, leukemia, lymphoproliferative disorders, chemotherapy and autoimmune deficiency syndrome (AIDS). To our knowledge cocaine induced bowel ischemia as a predisposing factor for Clostridium septicum sepsis has not been previous reported.

\section{CASE REPORT}

A 58-year-old white male presented to the Emergency Department with three days of worsening abdominal pain, constipation (no stooling for 4 days), decreased urine output, nausea and non-bloody emesis, and no rectal bleeding or diarrhea. Patient denied substance abuse, however family later reported daily cocaine binges and intermittent heroin use. Patient was alert and oriented, but uncomfortable. Vital signs were heart rate 125 beats per minute, respiratory rate 18 breaths per minute, blood pressure $99 / 65 \mathrm{mmHg}$ and oral temperature $36.9^{\circ} \mathrm{C}$. Pertinent examination findings included a tense abdomen without distention. There was diffuse tenderness with rebound and guarding and hypoactive bowel sounds. Laboratory tests showed white blood cell count 1,890 cells $/ \mathrm{mL}$ (4,800-10,800 cells $/ \mathrm{ml})$, absolute neutrophil count 0 cells $/ \mathrm{ml}$ $(2,400-8,100$ cells $/ \mathrm{ml})$, lactic acid $6.1 \mathrm{mmol} / \mathrm{L}(0.5 \mathrm{mmol} / \mathrm{L}$ $1.6 \mathrm{mmol} / \mathrm{L})$, anion gap $21 \mathrm{mmol} / \mathrm{L}(2-11 \mathrm{mmol} / \mathrm{L})$, and creatinine $3.2 \mathrm{mg} / \mathrm{dl}(0.6 \mathrm{mg} / \mathrm{dl}-1.3 \mathrm{mg} / \mathrm{dl})$. Urine drug screen was positive for cocaine. Abdomen and pelvis $\mathrm{CT}$ with oral contrast showed free intra-peritoneal gas, portal venous gas, gas within the mesenteric vessels, and pneumatosis in the distal ileum and entire length of the colon (see Figure 1).

*Correspondence: Evert A. Eriksson; Email: evsurgery@gmail.com; Address: Department of Surgery, Medical University of South Carolina, Charleston, South Carolina, United States. 
Patient was initially managed with fluid resuscitation and antibiotic administration, but then required emergent intubation, central venous access, and vasopressor support before being taken for exploratory laparotomy. Upon operative exploration, the entire small bowel from 10 centimeters distal of the ligament of Treitz to the terminal ileum was devitalized (see Figure 2). Also there was diffuse vessel thrombosis to the gastrocolic ligament and omentum (see Figure 3). Pneumatosis was appreciated in the ascending, transverse, and proximal descending colon. The sigmoid colon and proximal rectum were also found to be devitalized. The bowel necrosis was noted to progress during the exploration of the abdomen. Intraoperative intravenous fluorescein administration and inspection with a woods lamp was utilized to confirm no arterial flow to the distal small bowel or the entirety of the colon. There was no anatomical evidence of volvulus, intussusception, hernia, obstruction, or adhesions to explain the profuse distribution of bowel infarction. Due to the extensive bowel necrosis burden and unlikelihood of survival following complete resection of small bowel and colon, the family of the patient requested no further operative or resuscitative interventions. Shortly after discontinuing vasopressor support, the patient expired. Blood cultures were positive for Clostridium septicum.

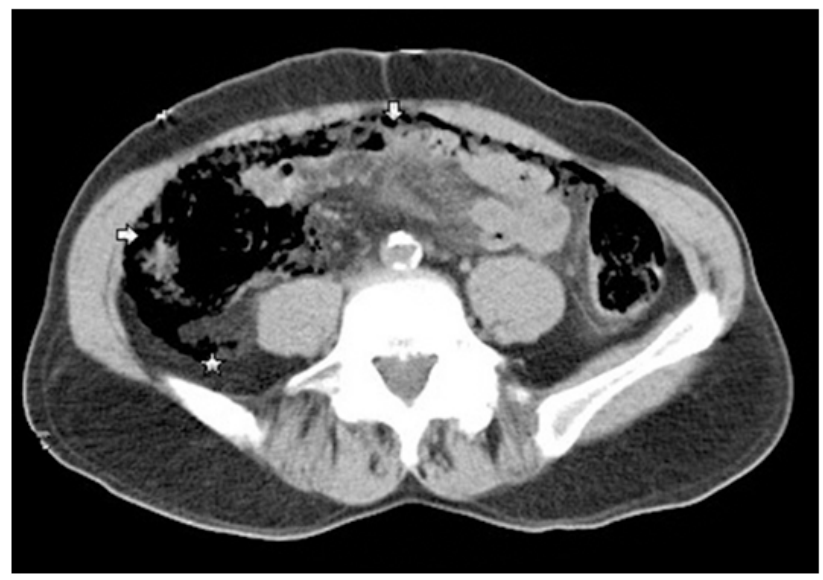

Figure 1. A computed tomography scan reveals pneumatosis coli (white arrows) and retroperitoneal free air (white star)

\section{Discussion}

Cocaine exhibits its systemic effects by blocking the reuptake of norepinephrine, dopamine, and serotonin at the pre-synaptic membrane, potentiating the effects of these neurotransmitters on postsynaptic receptors. Norepinephrine acts specifically on post-synaptic membranes of the sympathetic nervous system to cause sustained peripheral vasoconstriction, elevations in arterial pressure, and tachycardia.
These episodes of hemodynamic excitation are the presumed primary mechanism responsible for acute cerebrovascular accidents, myocardial infarctions, and ischemic organ complications. ${ }^{[2]}$

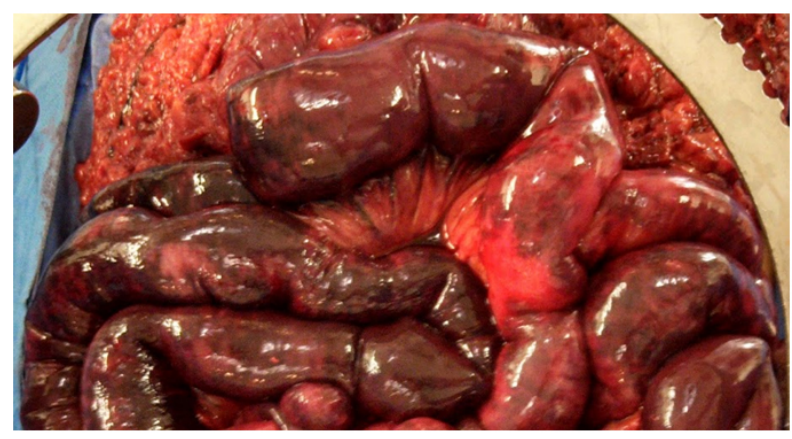

Figure 2. Ischemic small bowel

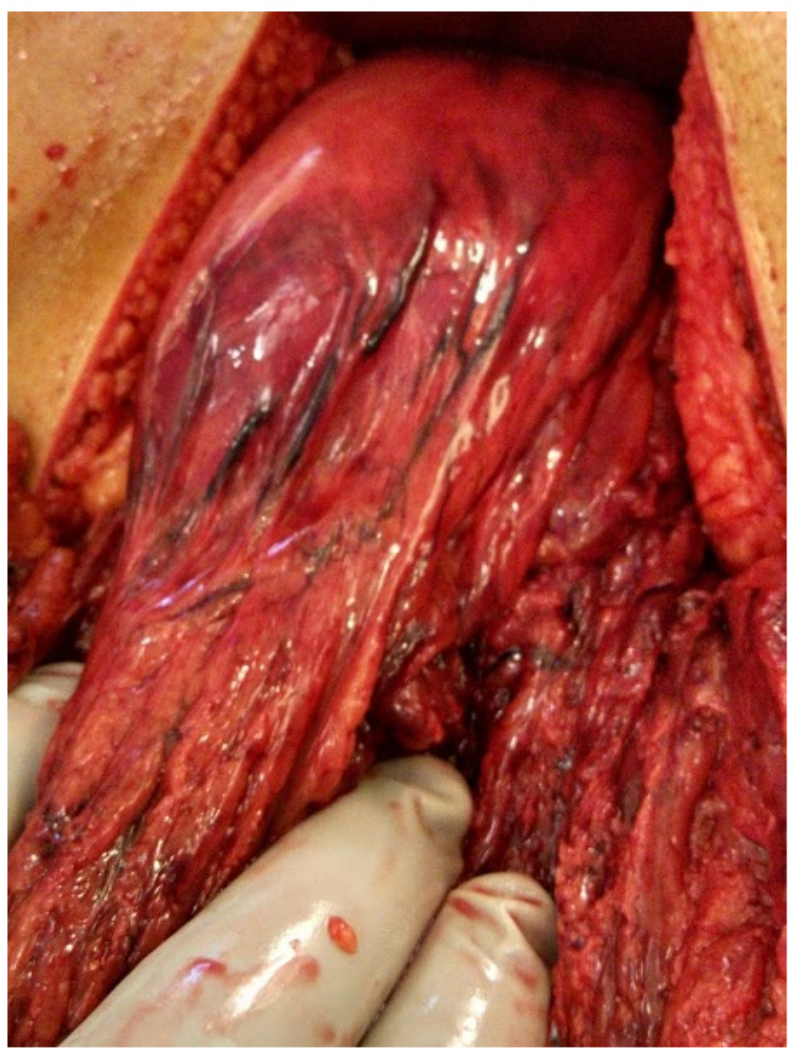

Figure 3. Thrombosed vasculature of the gastrocolic ligament and omentum

The incidence of bowel ischemia related to cocaine use is relatively rare, as compared to more frequent cardiovascular and cerebrovascular complications. The most common clinical features associated with cocaine related bowel ischemia include abdominal pain and tenderness, nausea, vomiting, and bloody diarrhea. ${ }^{[3,4]}$ Our patient manifested each of these except bloody diarrhea. 
Various mechanisms have been suggested to explain the ischemic gastrointestinal complications seen in cocaine abusers. The intestinal vascular bed is rich in alphaadrenergic receptors stimulated by excess norepinephrine that results in increased vascular resistance and decreased mesenteric flow when cocaine is administered ${ }^{[5]}$ A direct vascular constrictive effect of cocaine has also been described in gut mucosa due to influx of calcium across the endothelial cell membrane. Another risk for ischemia is the propensity for platelet aggregation and subsequent thrombus formation seen in cocaine administration. ${ }^{[6]}$ This increased vascular resistance to flow as well as increased platelet aggregation places patients at high risk for slowed venous return and subsequent mesenteric thrombosis as seen in our patient.

Laboratory evaluations of cocaine induced mesenteric ischemia commonly show an increase in the peripheral white blood cell count. In the largest case collection of 28 patients, the mean peripheral white blood cell count reported was 19,000 cells $/ \mathrm{ml}$ (range of $8,700-35,000$ cells $/ \mathrm{ml}$ ). ${ }^{[2]} \mathrm{In}$ our case, the patient presented with severe neutropenia and profound agranulocytosis. Interestingly, levamisole, an antihelminthic medication commonly used to "cut" cocaine, has resulted in recent outbreaks of agranulocytosis among cocaine users. ${ }^{[7,8]}$ Although there is no confirmation for levamisole being the cause of agranulocytosis exhibited in our patient, it is an interesting speculation.
Clostridium septicum is part of the normal bowel flora in $2 \%$ of health patients. ${ }^{[9]}$ Although occult gastrointestinal malignancy is most commonly associated with Clostridium septicum infection, any compromise to the gastrointestinal mucosa can lead to bacterial translocation and invasion especially in patients with concomitant neutropenia. ${ }^{[10]}$ Clostridium septicum produces many toxins with the $\alpha$-toxin being the most potent and responsible for hemolytic and necrotizing activities. ${ }^{[2,11]}$ The $\delta$-toxin (septicolysin) promotes platelet aggregation and impedes neutrophil migration. ${ }^{[12]}$ Most patients with non-traumatic gas gangrene secondary to Clostridium septicum present with rapidly progressive soft tissue myonecrosis, but as in our patient bowel ischemia alone can be the first manifestation. ${ }^{[13]}$ We hypothesize that the combined bowel ischemia, platelet aggregation and possible neutropenia effects of cocaine toxicity and the additional platelet aggregation and necrotizing activities of the Clostridium septicum toxins accounted for our patient presenting with rapidly progressive diffuse bowel necrosis instead of soft tissue myonecrosis.

We report a case of Clostridium septicum sepsis, diffuse bowel necrosis and perforation associated with cocaine abuse. To our knowledge, this is the first published case of cocainerelated bowel ischemia likely being the predisposing factor for Clostridium septicum sepsis and death.

\section{REFERENCES}

[1] Stevens DL, Aldape MJ, Bryant AE. Life-threatening clostridial infections. Anaerobe. 2012; 18: 254-259. PMid: 22120198. http: //dx.doi.org/10.1016/j. anaerobe.2011.11.001

[2] Cregler LL, Mark H. Medical complications of cocaine abuse. The New England journal of medicine. 1986; 315: 1495-1500. PMid: 3537786. http://dx.doi.org/10.1056/NEJM1986120431523 27

[3] Linder JD, Monkemuller KE, Raijman I, et al. Cocaine-associated ischemic colitis. Southern medical journal. 2000; 93: 909-913. PMid: 11005354. http://dx.doi.org/10.1097/00007611-2000090 00-00015

[4] Niazi M, Kondru A, Levy J, et al Spectrum of ischemic colitis in cocaine users. Digestive diseases and sciences. 1997; 42: 1537-1541. PMid: 9246060. http://dx.doi.org/10.1023/A : 1018839415743

[5] Isner JM, Chokshi SK. Cocaine and vasospasm. The New England journal of medicine. 1989; 321: 1604-1606. PMid: 2586556. http://dx.doi.org/10.1056/NEJM198912073212309

[6] Rezkalla SH, Mazza JJ, Kloner RA, et al. Effects of cocaine on human platelets in healthy subjects. The American journal of cardiology. 1993; 72: 243-246. http://dx.doi.org/10.1016/0002-9 149 (93) 90173-A

[7] Chang A, Osterloh J, Thomas J. Levamisole: a dangerous new cocaine adulterant. Clinical pharmacology and therapeutics. 2010; 88:
408-411. PMid: 20668440. http://dx.doi.org/10.1038/clpt. 2010. 156

[8] Agranulocytosis associated with cocaine use - four States, March 2008-November 2009. MMWR Morbidity and mortality weekly report. 2009; 58: 1381-1385. PMid: 20019655.

[9] Kiel N, Ho V, Pascoe A. A case of gas gangrene in an immunosuppressed Crohn's patient. World journal of gastroenterology. 2011; 17: 3856-3858. PMid: 21987630. http://dx.doi.org/10.3748 /wjg.v17.i33.3856

[10] Yeong ML, Nicholson GI. Clostridium septicum infection in neutropenic enterocolitis. Pathology. 1988; 20: 194-197. http://dx.d oi.org/10.3109/00313028809066634

[11] Rimawi BH, Graybill W, Pierce JY, et al. Necrotizing Fasciitis and Toxic Shock Syndrome from Clostridium septicum following a Term Cesarean Delivery. Case reports in obstetrics and gynecology. 2014; 2014: 724302. PMid: 24822140. http://dx.doi.org/10.1155 /2014/724302

[12] Bryant AE, Stevens DL. Clostridial myonecrosis: new insights in pathogenesis and management. Current infectious disease reports. 2010; 12: 383-391. PMid: 21308521. http://dx.doi.org/10.10 07/s11908-010-0127-y

[13] Wu YE, Baras A, Cornish T, et al. Fatal spontaneous Clostridium septicum gas gangrene: a possible association with iatrogenic gastric acid suppression. Archives of pathology \& laboratory medicine. 2014; 138: 837-841. PMid: 24878026. http://dx.doi.org/10. 5858/arpa. 2013-0104-CR 